\title{
Dual-band RFID tag antenna based on the Hilbert-curve fractal for HF and UHF applications
}

ISSN 1751-858X

Received on 7th May 2015

Accepted on 23rd August 2015 doi: 10.1049/iet-cds.2015.0221

www.ietdl.org

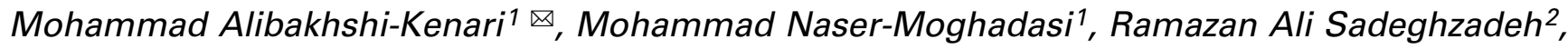 \\ Bal S. Virdee ${ }^{3}$, Ernesto Limiti ${ }^{4}$ \\ ${ }^{1}$ Faculty of Engineering, Science and Research Branch, Islamic Azad University, Tehran, Iran \\ ${ }^{2}$ Department of Electrical and Computer Engineering, K. N. Toosi University of Tech., Tehran, Iran \\ ${ }^{3}$ Centre for Communications Technology, London Metropolitan University, London N7 8DB, UK \\ ${ }^{4}$ Dipartimento di Ingegneria Elettronica, Università degli Studi di Roma Tor Vergata, Via del Politecnico 1, 00133 Roma, Italy \\ 凶-mail: makenari@mtu.edu
}

\begin{abstract}
A novel single-radiator card-type tag is proposed which is constructed using a series Hilbert-curve loop and matched stub for high frequency (HF)/ultra high frequency (UHF) dual-band radio frequency identification (RFID) positioning applications. This is achieved by merging the series Hilbert-curve for implementing the HF coil antenna, and square loop structure for implementing the UHF antenna to form a single RFID tag radiator. The RFID tag has directivity of $1.75 \mathrm{dBi}$ at $25 \mathrm{MHz}, 2.65 \mathrm{dBi}$ at $785 \mathrm{MHz}, 2.82 \mathrm{MHz}$ at $835 \mathrm{MHz}$ and $2.75 \mathrm{dBi}$ at $925 \mathrm{MHz}$. The tag exhibits circular polarisation with $-3 \mathrm{~dB}$ axial-ratio bandwidth of $14,480,605$ and $455 \mathrm{MHz}$ at 25, 785, 835 and $925 \mathrm{MHz}$, respectively. The radiation characteristics of the RFID tag is quasi-omnidirectional in its two orthogonal planes. Impedance matching circuits for the HF/UHF dual-band RFID tag are designed for optimal power transfer with the microchip. The resulting dual-band tag is highly compact in size and possesses good overall performance which makes it suitable for diverse applications.
\end{abstract}

\section{Introduction}

Radio frequency identification (RFID) is a contactless method for data transfer in object identification. In RFID systems, data is transferred between a transponder and a reader unit wirelessly by means of electromagnetic waves. Interest in RFID systems and its applications is rapidly growing [1-3]. Operating frequency bands, including LF (125-134 and 140-148.5 kHz), HF (13.56 MHz) and UHF (865-965 MHz) have been used for various supply chains [4-14]. Active and WiFi readers have been assigned the $433 \mathrm{MHz}$ and $2.45 \mathrm{GHz}$ bands, respectively. Other than the reader antennas, the requirements of tag antennas are necessary. UHF tag offer benefits of long read range and low cost, which makes it an excellent candidate for use in distribution and logistics systems.

Meander-line antennas were commonly used for UHF tags, due to the characteristics of high-gain, omni-directionality, planarity and relatively small surface size [4]. The inductive impedance of the tag antenna is commonly used for matching the capacitive terminations of integrated circuit microchip [5-12]. The dual-band UHF tags operating at the frequency bands of 867 and $915 \mathrm{GHz}$ are developed for long-range applications [13, 14]. Environmental stresses affecting the UHF tag antenna's impedance, loss and radiation characteristics have been studied resulting from the impact on the ink film and paper substrate [15].

Recently, the HF/UHF dual-band RFID tags were introduced for various applications such as logistics, inventory management and bio-engineering, etc. [16-31]. Card-type dual-band RFID tags have also been demonstrated for positioning applications [17-31]. In dual feeding port-type tags, the spiral coil and meander-line dipole are used as the HF antenna and the UHF antenna, respectively, where the meandered dipole antenna is located outside the HF coil [17]. It has shown the UHF dipole antenna can be located inside the HF coil [18]. In another variation reported in [19], a shorted loop slot antenna is used for operation in the UHF-band, and a coil for operation in the HF-band. This technique allows the use of the HF coils, excited by an S-dipole element, as a part of the UHF antenna in [20]. Antenna configuration for HF and UHF-band hybrid card-type RFID tags proposed in [25] utilises a coil for operation in the HF-band as a ground conductor, and acts as a monopole antenna in the UHF-band. Capacitive coupling of the coil windings at the vicinity of the UHF feed point helps to reduce the dependency of the radiation efficiency on the coil's dimensions and to obtain higher radiation efficiency in the UHF band. In [26] RFID tag design is implemented on a credit-card size single-layer support, a spiral coil along the edges of the card is designed to handle the HF $(13.56 \mathrm{MHz})$ near-field coupling, and the UHF antenna is placed inside the coil instead of outside. In addition, a diagonal symmetric design consisting of two meander-lines inside the spiral coil is adopted for UHF band. This structure supports multiple resonance modes around $915 \mathrm{MHz}$ to broaden the working bandwidth (BW) under the large inductive circumstance from the HF coil. For mono feeding port type, the combination of two separated antennas fed by a single chip operating in two frequency bands is reported in [27]. The above RFID tags consist of two individual radiators and their radiation efficiency is limited because of the large coupling between the individual radiators, and the connection between RFID chip and HF coil. Therefore, two key challenges are faced, i.e. the development of HF/UHF dual-band RFID tag with nearly 65 times frequency difference in a single radiator, and eradication of the physical connection between the RFID chip and the HF coil.

Since the conventional HF coils in RFID tags are planar spirals, the total length of the spiral are limited in the available area of the tag. The tag also needs to be connected to the RFID chip. To extend the length of the HF coils as well as increase its inductance, space-filling technique needs to be employed. The Hilbert-curve is a well-established space-filling fractal which has been effectively used to design miniature radiators [32-40]. The Hilbert-curve structure is constructed from a metallic strip which is compacted within the area of the patch. The iteration order of the curve increases the density or space-filling property of the curve. A fractal tag antenna constructed with series Hilbert-curve and self-complementary configuration was proposed for UHF RFID applications [41].

Based on the card-type dual-band tags [17-31], and the series Hilbert-curve tag [41], an alternative card-type dual-band RFID 


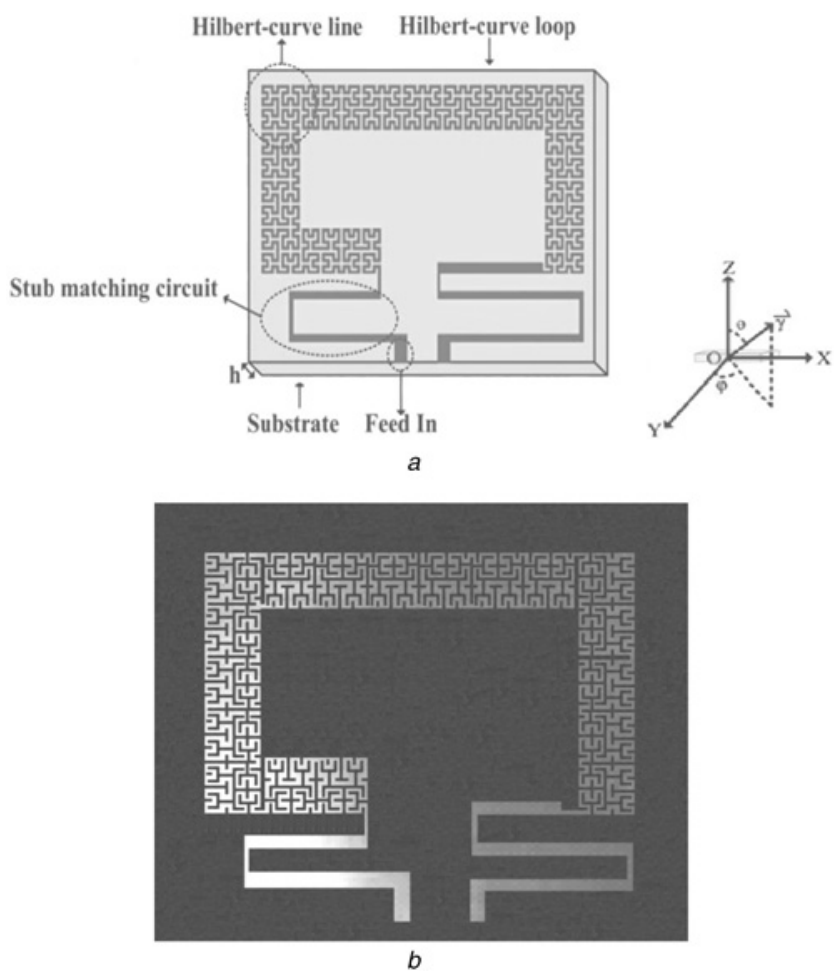

Fig. 1 Hilbert-curve loop tag antenna in the zx-plane

$a$ Simulation layout

$b$ Fabricated RFID tag

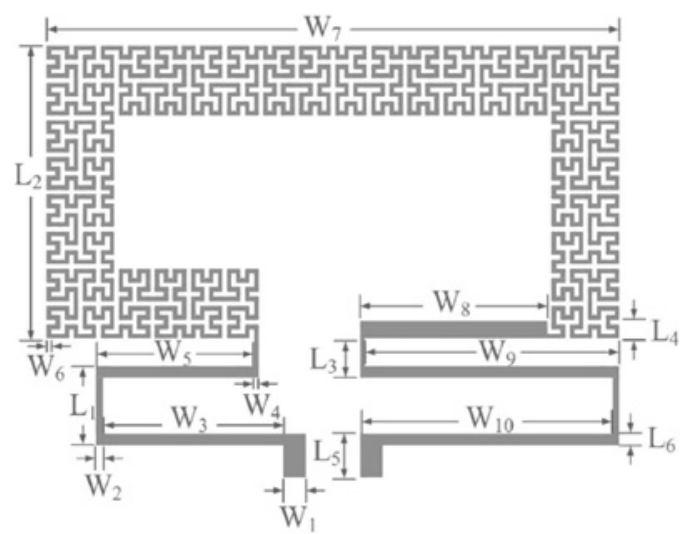

Fig. 2 Design parameters of the Hilbert-curve loop tag

tag is proposed in this paper. The proposed tag merges the series Hilbert-curve for HF coil antenna and square loop patch for UHF antenna to form a single radiator in order to obtain a compact tag with dual-band performance. The antenna's axial-ratio (AR) spectrum confirms its circular polarisation characteristics. The inductive dual-band characteristics of frequency response and directivity of the radiation patterns and polarisation are presented. Conjugated matching circuit designs are presented for the HF/UHF dual-band tag. The proposed dual-band RFID tag operating at 25, 785,835 and $925 \mathrm{MHz}$ is applicable for various applications from near-field communications for ticketing, payment and data transfer to far-field applications like inventory and asset management.

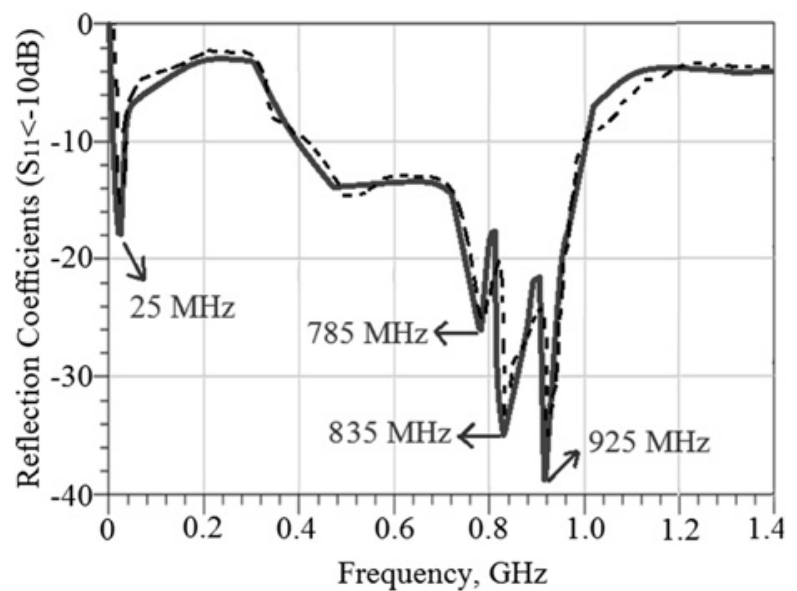

Fig. 3 Simulated (solid-line) and measured (dashed-line) reflection-coefficient response

\section{Dual-band series Hilbert-curve loop tag and matched stub}

Series Hilbert-curve loop tag antenna is constructed with substrate, Hilbert-curve line, loop structure and matched stub network, as shown in Fig. 1. The proposed fractal is implemented with the third-order Hilbert-curve. The physical parameters defining the antenna in Fig. 2 are listed in Table 1. The thickness $(h)$ of Rogers/RT Duroid5880 substrate is $0.8 \mathrm{~mm}$ and its relative permittivity $\left(\varepsilon_{\mathrm{r}}\right)$ is 2.2 .

The series Hilbert-curve loop structure in Fig. 1 serves simultaneously two frequency bands, namely HF and UHF-bands. In contrast to the common RFID tags consisting of two individual antennas [17-31], the proposed dual-band structure comprises a single radiator that operates in the HF and UHF-bands.

\subsection{HF coil antenna}

For the $25 \mathrm{MHz}$ band RFID tag a series Hilbert-curve line is used as the HF coil antenna. The received magnetic field that is aligned perpendicular to the coil plane induces a voltage in the winding of the Hilbert-curve. According to the law of induction, the voltage can be increased by enlarging the area of the Hilbert-curve in order to collect a larger magnetic flux. It is therefore important that the series Hilbert-curve line is space-filling over the outermost region of the tag.

The quality-factor $\left(Q_{\mathrm{HF}}\right)$ of the $\mathrm{HF}$ coil antenna is determined by the total inductance and the resistive losses in the coil. It is defined in terms of stored energy and power loss. The $Q_{\mathrm{HF}}$ is related to the antenna's centre frequency $\left(f_{0}\right)$ and $3 \mathrm{~dB} \mathrm{BW}$ according to $Q_{\mathrm{HF}}=$ $f_{0} / \mathrm{BW}$. This makes the quality-factor available for measurement. The value of $Q_{\mathrm{HF}}$ increases as the losses decrease leading to a high resistance. The input resistance measures the power supplied to maintain a given voltage level. In the case of a resonant HF antenna, the resonant frequency is determined by the inductance and the capacitance of the $L C$ circuits, $f_{0}=1 /(2 \sqrt{L C})$.

\subsection{UHF antenna}

For UHF-band, the main design parameter of the Hilbert-curve loop antenna is the length of the loop resonator, which is folded inside a rectangular area. The length determines the self-resonant frequency of the UHF antenna. A standing-wave can be excited in the loop

Table 1 Dimensions of Hilbert-curve loop tag (in terms of millimetres)

\begin{tabular}{|c|c|c|c|c|c|c|c|c|c|c|c|c|c|c|c|}
\hline $\begin{array}{l}L_{1} \\
8\end{array}$ & $\begin{array}{c}L_{2} \\
27.4\end{array}$ & $\begin{array}{c}L_{3} \\
4\end{array}$ & $\begin{array}{c}L_{4} \\
1.8\end{array}$ & $\begin{array}{c}L_{5} \\
4.2\end{array}$ & $\begin{array}{l}L_{6} \\
1.2\end{array}$ & $\begin{array}{l}W_{1} \\
2.5\end{array}$ & $\begin{array}{l}W_{2} \\
0.9\end{array}$ & $\begin{array}{c}W_{3} \\
18.6\end{array}$ & $\begin{array}{c}W_{4} \\
0.65\end{array}$ & $\begin{array}{c}W_{5} \\
16.5\end{array}$ & $\begin{array}{c}W_{6} \\
0.65\end{array}$ & $\begin{array}{l}W_{7} \\
56\end{array}$ & $\begin{array}{c}W_{8} \\
18\end{array}$ & $\begin{array}{l}W_{9} \\
24\end{array}$ & $\begin{array}{l}W_{10} \\
24.1\end{array}$ \\
\hline
\end{tabular}



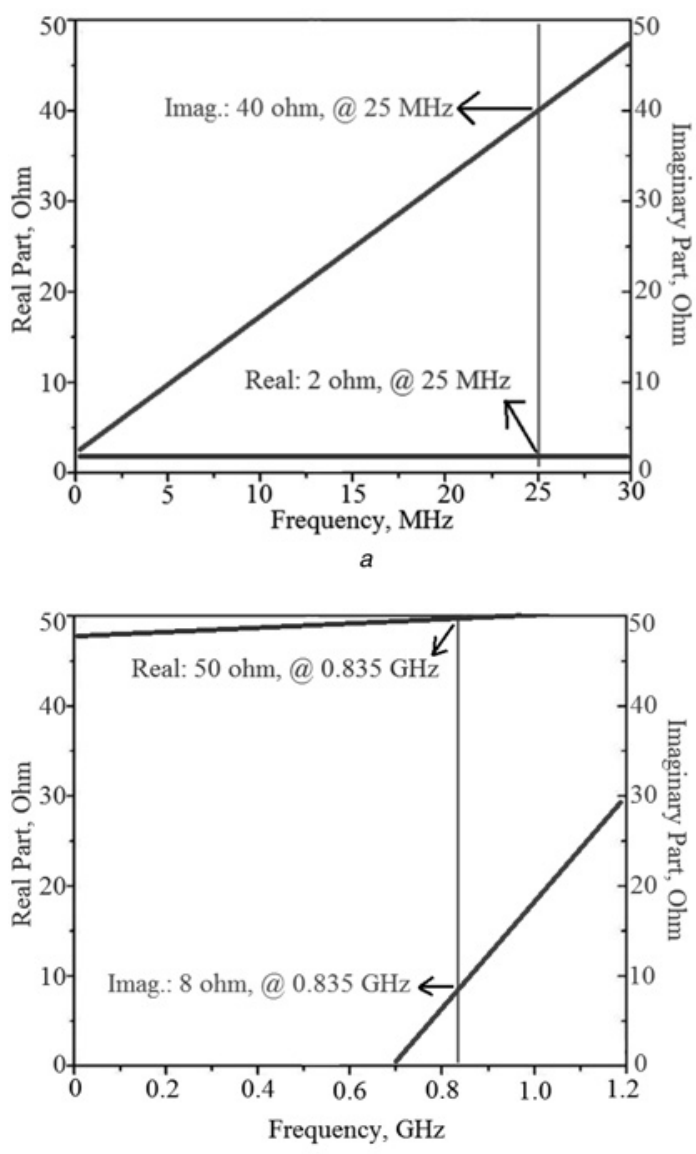

c

Fig. 4 Measured results of impedance spectrum at

a $25 \mathrm{MHz}$

b $785 \mathrm{MHz}$

c $835 \mathrm{MHz}$

d $925 \mathrm{MHz}$

by applying electric energy along the loop. Radiation of the tag is due to the electric current flowing through the conductive loop. The characteristics of HF/UHF dual-band can be observed in the current distributions. Matching the tag to the microchip is necessary to optimise power transfer. This can be implemented using microstrip stub network which is used to replace discrete lumped components because at UHF frequencies lumped components perform poorly due to parasitic reactance.

\section{Simulation and measurement results}

The return-loss spectrum of the proposed RFID tag, shown in Fig. 3, was obtained using the commercial software HFSS by Ansys [42]. There is good agreement between the simulation and measurement results. The measured results show the tag operates across the frequency ranges of $12.5-37.5 \mathrm{MHz}$ and $0.4-1.4 \mathrm{GHz}$ for return-loss better than $-10 \mathrm{~dB}$. The centre frequency of the four resonant modes in the reflection-coefficient response are $f_{\mathrm{c}}=25$ $\mathrm{MHz}, f_{\mathrm{c}}=785 \mathrm{MHz}(760-815 \mathrm{MHz}), f_{\mathrm{c}}=835 \mathrm{GHz}(822-905 \mathrm{MHz})$ and $f_{\mathrm{c}}=925 \mathrm{MHz}(918-1000 \mathrm{MHz})$. The proposed RFID tag finds application in the HF and UHF-bands. The band centred at $25 \mathrm{MHz}$ is suitable for near-field communication.

The impedance analysis results in Fig. 4 shows the real part of the impedance having a maximum value of 49,50 and $48 \Omega$ at 785,835 and $925 \mathrm{MHz}$, respectively, and the imaginary part of the impedance presenting an inductive characteristic of $+9,+8$ and $+11 \Omega$ at 785 , 835 and $925 \mathrm{MHz}$ frequencies, respectively. The inductive impedance can be used to match the capacitive RFID chip. At $25 \mathrm{MHz}$ the real part of the impedance is $2 \Omega$, and the imaginary
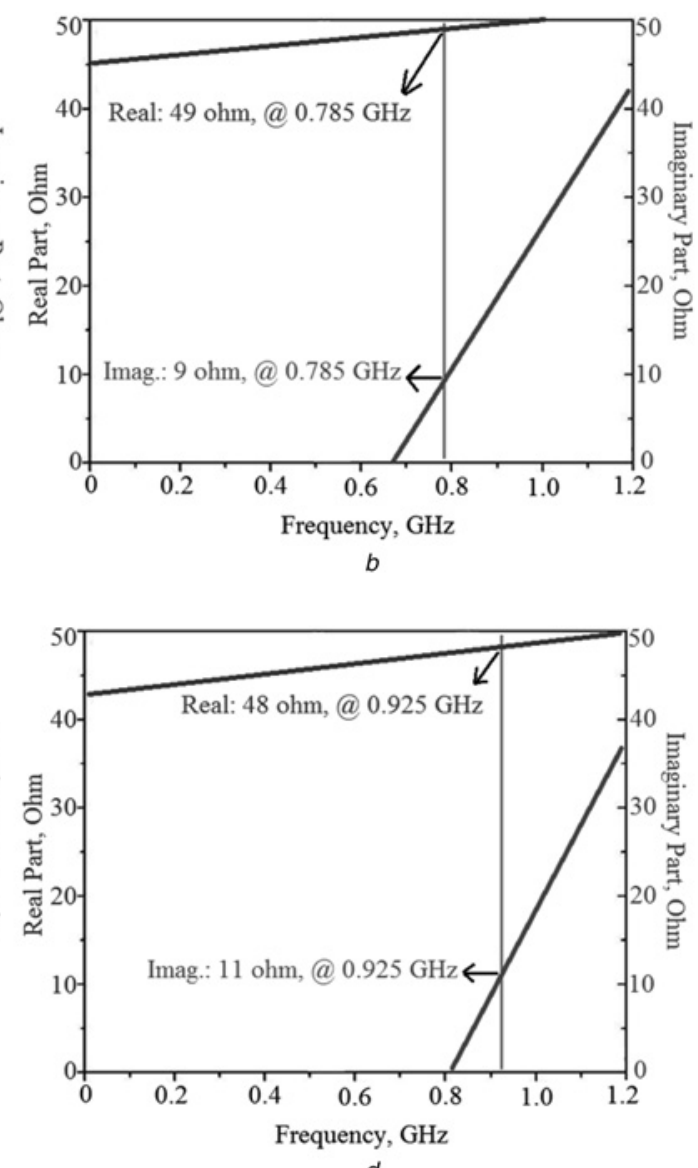

d part is $40 \Omega$, as shown in Fig. $4 a$. For the tag antenna impedance $Z_{\mathrm{A}(\mathrm{HF})}=R_{\mathrm{A}}+\mathrm{j} X_{\mathrm{A}}$, the quality-factor $Q_{\mathrm{A}}$ is expressed by:

$$
Q_{\mathrm{A}}=\frac{X_{\mathrm{A}}}{R_{\mathrm{A}}}
$$

$Q_{\mathrm{A}}$ is a figure-of-merit indicating that when the antenna is close to resonance, that is $X_{\mathrm{A}}$ is close to zero, the quality-factor is almost zero. This means that at that particular frequency the impedance is almost real.

The available $Q_{\mathrm{A}}=25.1$ at $25 \mathrm{MHz}$ is obtained for matching the IC-chip by designing the $L C$ circuit. From Fig. 4 the quality-factor $Q_{\mathrm{A}}=0.15, \quad 0.17$ and 0.165 are 785,835 and $925 \mathrm{MHz}$, respectively. The current density distribution over the planar structure is shown in Fig. 5. It provides an insight of how the $\mathrm{HF} / \mathrm{UHF}$ dual-band structure affects the current at different frequencies. The total length of the series Hilbert-curve excited with $1 / 20 \lambda_{g}$ is presented in Fig. $5 a$, and the mean circumstance of the loop equated to $1 \lambda_{\mathrm{g}}$ is operated in Fig. $5 b$. Since the total length of series Hilbert-curve is less than $1 / 10 \lambda_{\mathrm{g}}$, it belongs to the small antenna category.

The antenna under test was located on the $z x$-plane, shown in Fig. 1, and the feeding line is located along the $x$-axis. The radiation patterns are obtained by an automatic measurement system in an anechoic chamber. The two radiation patterns of the tag antenna were obtained along the $x z$ - and $y z$-planes. The two-plane radiation patterns at $25,785,835$ and $925 \mathrm{MHz}$ in the HF and UHF bands are given in Fig. 6.

The simulated and measured radiation patterns of the proposed antenna in the $x z$ - and $y z$-planes at $25,785,835$ and $925 \mathrm{MHz}$ 

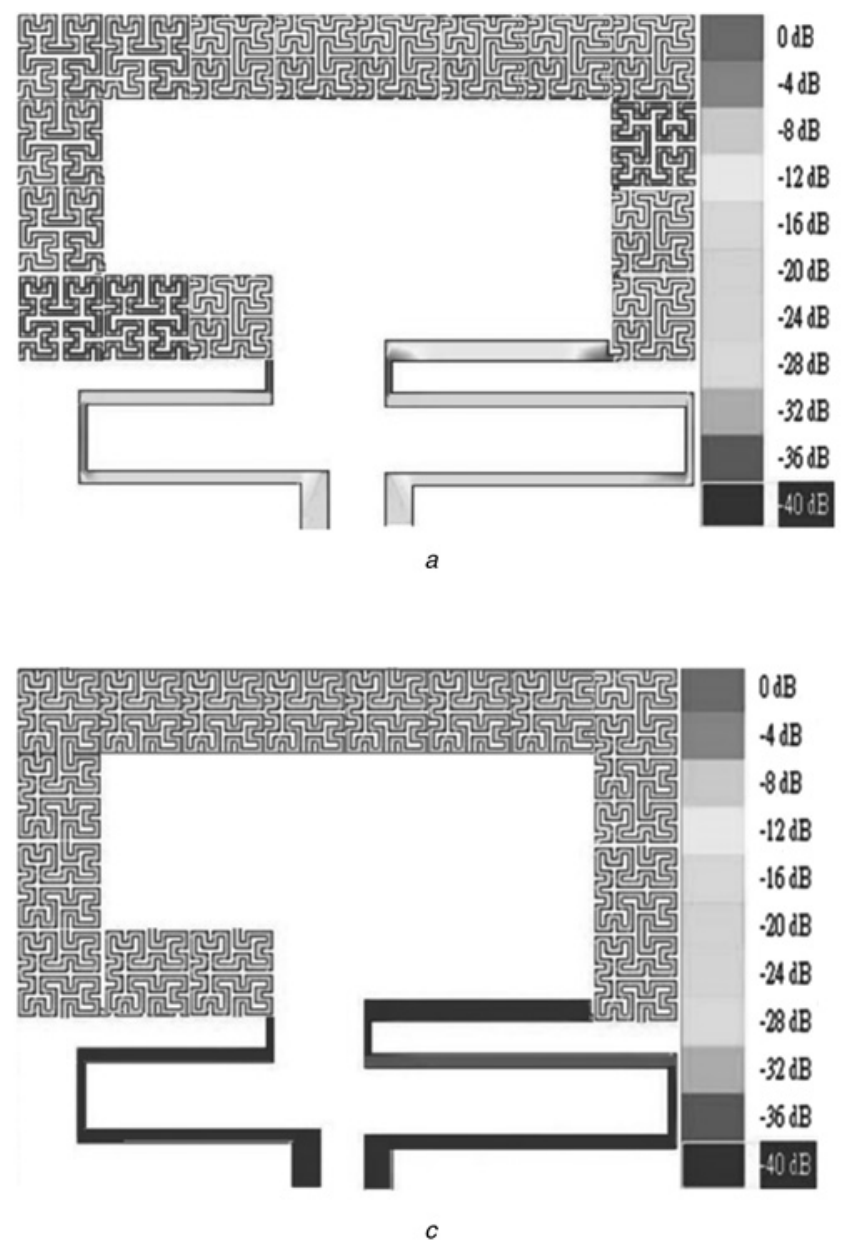

Fig. 5 Current distributions at

a $25 \mathrm{MHz}$

b $785 \mathrm{MHz}$

c $835 \mathrm{MHz}$

$d 925 \mathrm{MHz}$

over the HF and UHF bands are shown in Fig. 6. There is good agreement between the simulation and measurement results. The measured radiation in the $x z$-plane is quasi-omnidirectional at 25 , 785 and $835 \mathrm{MHz}$; however, the radiation is bidirectional at $925 \mathrm{GHz}$. In the $y z$-plane, the radiation pattern is omnidirectional at 25,785 and $925 \mathrm{MHz}$, and distinctly bidirectional at $835 \mathrm{MHz}$. Fig. 7 shows that the tag antenna has directivity of $1.75 \mathrm{dBi}$ at 25 $\mathrm{MHz}$ in the $\mathrm{HF}$ band, and 2.65, 2.82 and $2.75 \mathrm{dBi}$ at 785,835 and $925 \mathrm{MHz}$ in the UHF band.

Circular polarisation wave is generated by exciting two orthogonal modes in the RFID tag. This is achieved with the orthogonal arrangement of the Hilbert-curve tag. The AR spectrum of the polarisation related to various angles $(\varphi$ and $\theta$ ) is presented in Fig. 8. The minimum AR is observed at 785,835 and $925 \mathrm{MHz}$ at $\varphi=0^{\circ}, \theta=95^{\circ}$ with corresponding $-3 \mathrm{~dB}$ AR BW of $480 \mathrm{MHz}$ (560-1040 MHz), $605 \mathrm{MHz}(515-1120 \mathrm{MHz})$ and $455 \mathrm{MHz}(620-$ $1075 \mathrm{MHz}$ ). The minimum AR is observed at $25 \mathrm{MHz}$ at $\varphi=0^{\circ}$, $\theta=92^{\circ}$ with corresponding $-3 \mathrm{~dB}$ AR BW of $14 \mathrm{MHz}(18-32$ $\mathrm{MHz}$. Thus, the proposed antenna can be applied to diversity operation.

\section{Conjugate matching design}

\subsection{UHF matching circuit}

The maximum activation distance of the tag for the given frequency is given by $[25,26]$
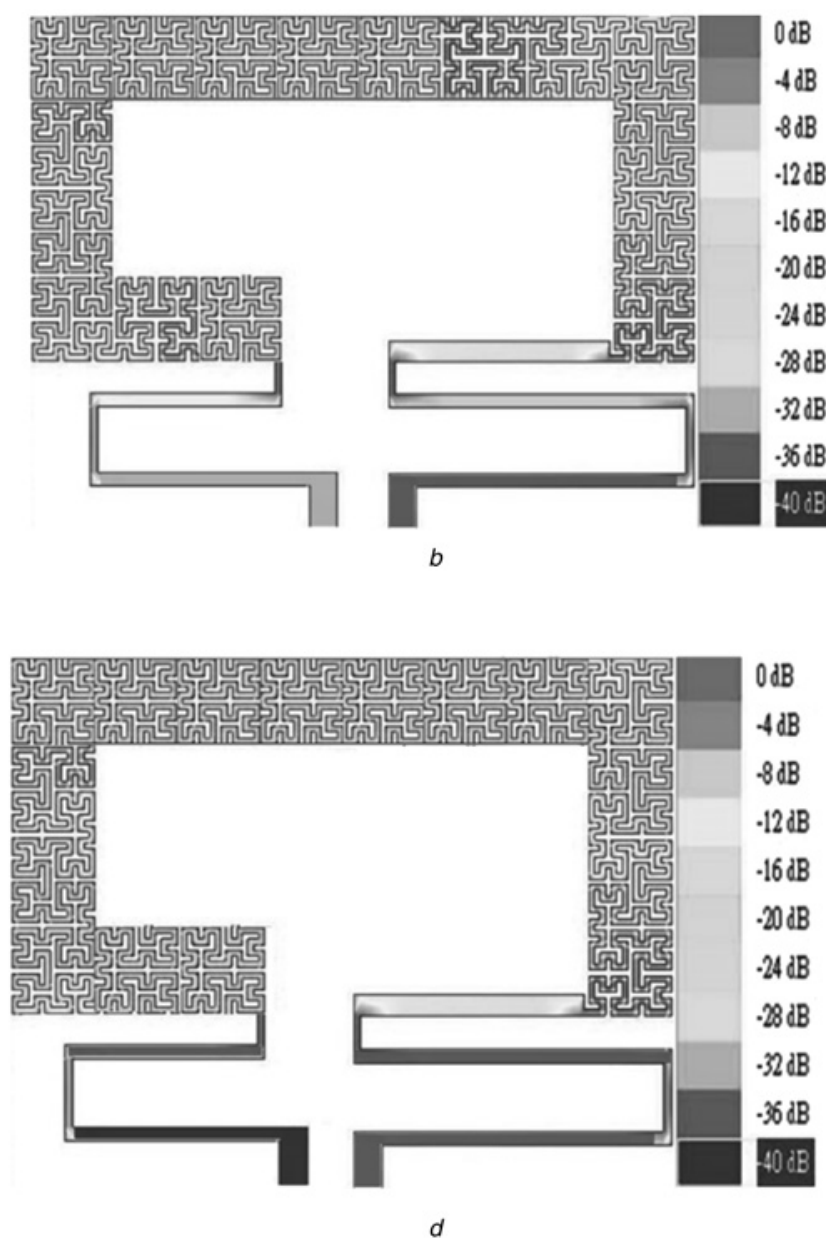

$\mathrm{OdB}$

$-8 \mathrm{~dB}$

$12 \mathrm{~dB}$

$-16 \mathrm{~dB}$

$20 \mathrm{~dB}$

$24 \mathrm{~dB}$

$.28 \mathrm{~dB}$

$.32 \mathrm{~dB}$

$.36 \mathrm{~dB}$ $40 \mathrm{~dB}$

$d$

$$
d_{\max }=\frac{c}{4 \pi f} \sqrt{\frac{\text { EIRP }_{\mathrm{r}}}{P_{\text {chip }}} \tau G}
$$

where EIRP $P_{\mathrm{r}}$ is the effective transmitted power of the reader, $P_{\text {chip }}$ is the sensitivity of the tag microchip, $G$ is the maximum tag antenna gain, and the power transmission factor $\tau$ is given by

$$
\tau=\frac{4 R_{\mathrm{tag}} R_{\mathrm{A}}}{\left|X_{\text {chip }}+X_{\mathrm{A}}\right|^{2}} \leq 1
$$

with tag antenna impedance $\left(Z_{\mathrm{A}(\mathrm{UHF})}=R_{\mathrm{A}}+\mathrm{j} X_{\mathrm{A}}\right)$ and microchip impedance $\left(Z_{\text {chip }}=R_{\text {chip }}+\mathrm{j} X_{\text {chip }}\right)$.

The microchip NSC MM9647 can be applied to the tag in UHF band. Its impedance is $Z_{\text {chip }}=80-\mathrm{j} 120 \Omega$ [43]. As the effective transmitted power EIRP $P_{\mathrm{r}}$ of reader is $1.2 \mathrm{~W}$, the sensitivity $P_{\text {chip }}$ of tag microchip is $-10 \mathrm{dBm}$, the maximum tag antenna gain $G=$ $3.35 \mathrm{dBi}$, and the activation distance $d$ with boundary condition $d_{\max }=5 \mathrm{~m}$, therefore from (2) the power transmission factor $\tau=$ 0.95. The tag antenna impedance from Fig. 4 is $Z_{\mathrm{A}(\mathrm{UHF})}=49+\mathrm{j} 9 \Omega$ at $785 \mathrm{MHz}, Z_{\mathrm{A}(\mathrm{UHF})}=50+\mathrm{j} 8 \Omega$ at $835 \mathrm{MHz}$ and $Z_{\mathrm{A}(\mathrm{UHF})}=48+\mathrm{j}$ $11 \Omega$ at $925 \mathrm{MHz}$, hence from (3) the necessary microchip impedance $Z_{\text {chip }}=80-\mathrm{j} 120 \Omega$ enables conjugate matching to be determined. 

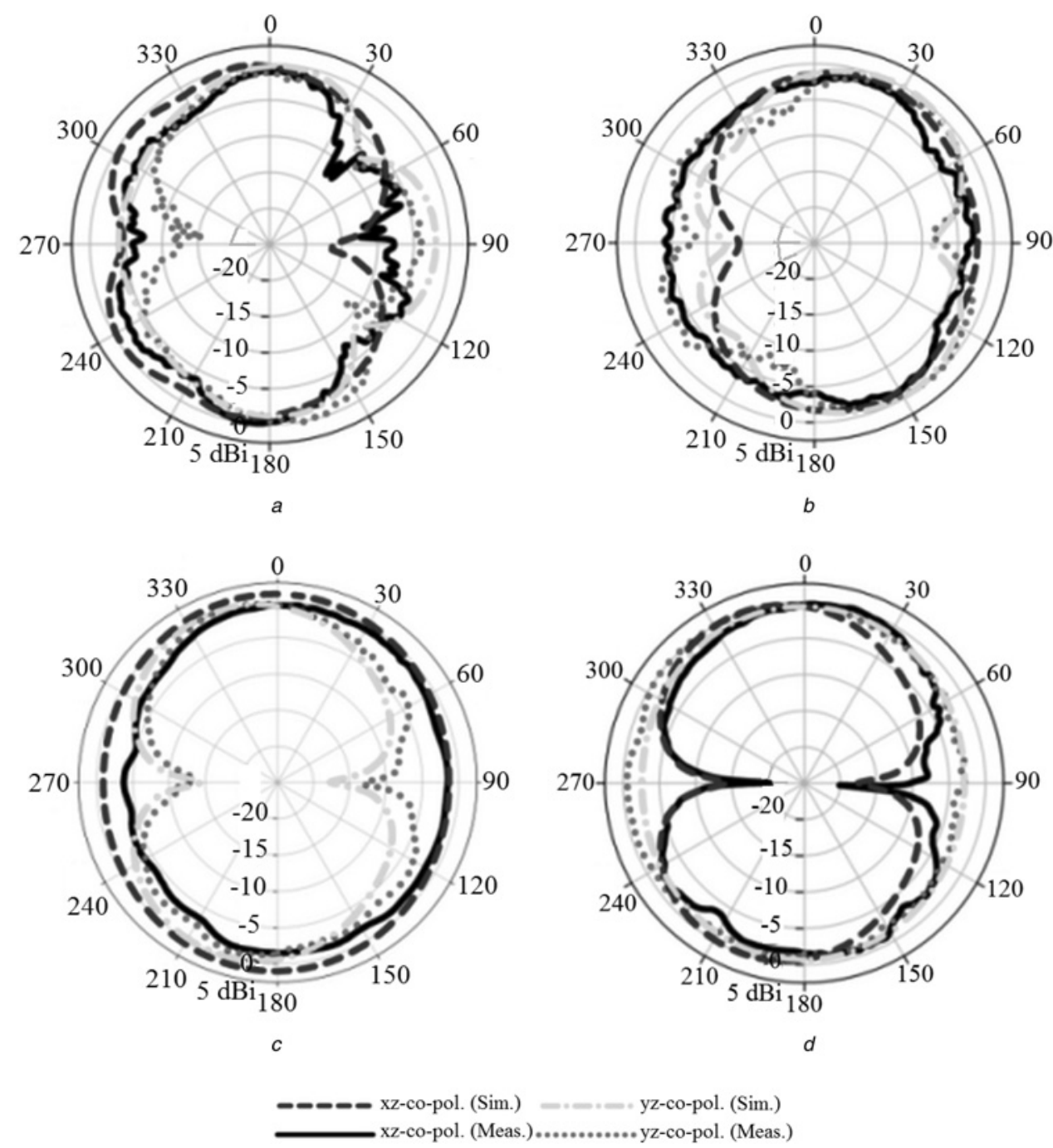

Fig. 6 Radiation patterns of the RFID tag at

a $25 \mathrm{MHz}$

b $785 \mathrm{MHz}$

c $835 \mathrm{MHz}$

$d 925 \mathrm{MHz}$

\subsection{HF matching circuit}

Another example of designing a matching network is presented using Tag-it ${ }^{\mathrm{TM}}$ HF-I standard transponder microchip which has capacitance

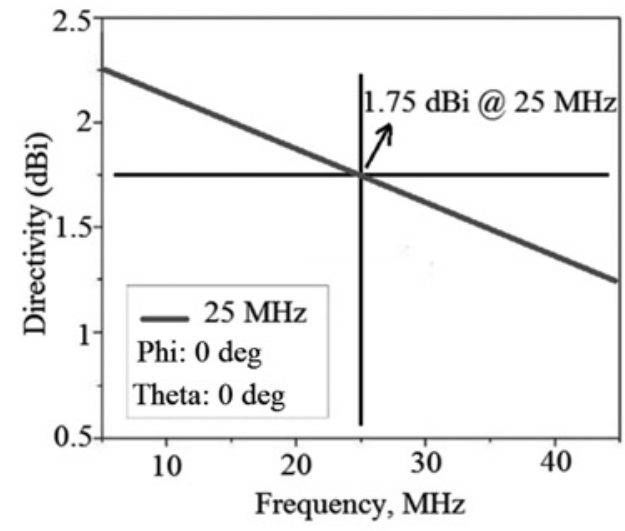

$C_{\text {chip }}=2.85 \mathrm{pF}$ at $25 \mathrm{MHz}$ [44]. The tag antenna's impedance from Fig. $4 a$ is $Z_{\mathrm{A}(\mathrm{HF})}=2+\mathrm{j} 40 \Omega$, where $L_{\mathrm{A}}=0.45 \mu \mathrm{H}$ and $R_{\mathrm{A}}=2 \Omega$. The impedance matching $L C$ circuit is shown in Fig. 9. The desired shunt capacitor $C_{\text {shunt }}=0.42 \mathrm{nF}$ is obtained from (4) and (5). From

Fig. 7 Directivity at

a $25 \mathrm{MHz}$ in the $\mathrm{HF}$ band

$b 785,835$ and $925 \mathrm{MHz}$ in the UHF bands

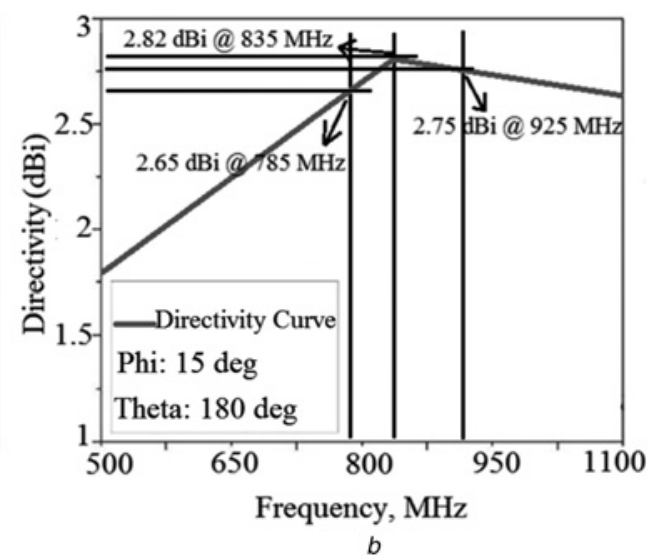



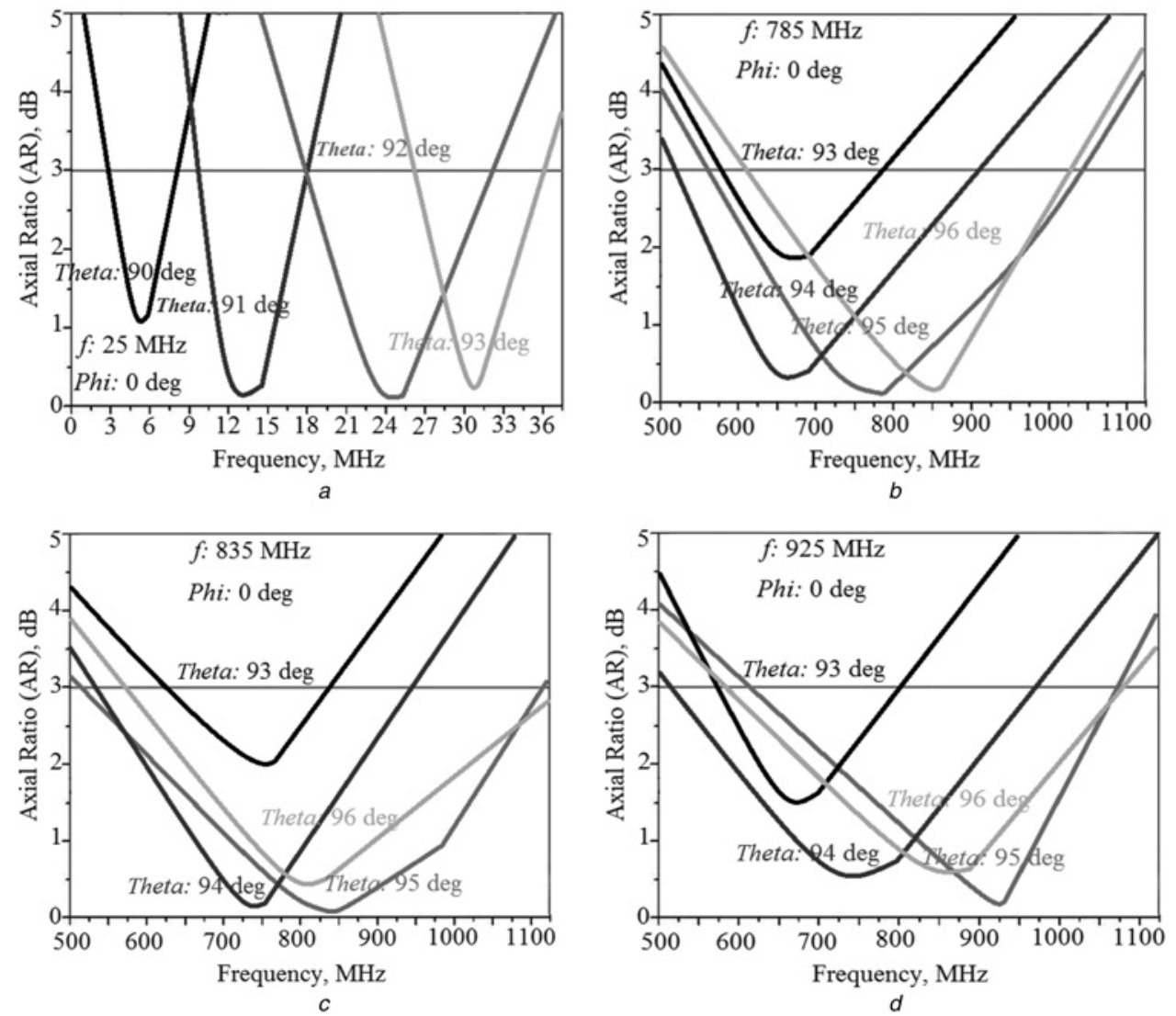

Fig. 8 AR spectrum centred at

a $25 \mathrm{MHz}$

b $785 \mathrm{MHz}$

c $835 \mathrm{MHz}$

$d 925 \mathrm{MHz}$

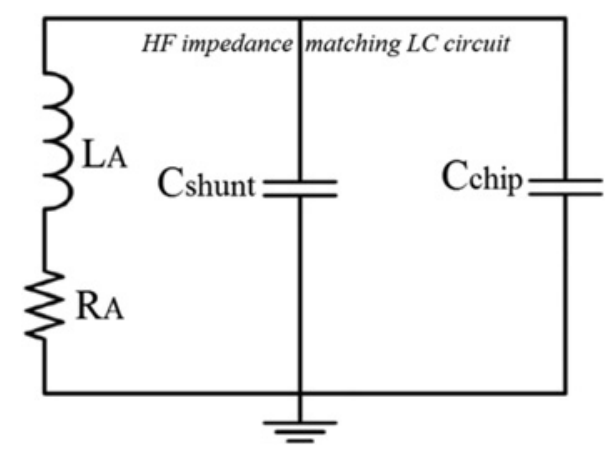

Fig. 9 HF impedance matching LC circuit

(6) the total circuit factor $Q_{\mathrm{T}}$ is 25.1 .

$$
\begin{gathered}
L_{\mathrm{A}}=\frac{\mathrm{j} X_{\mathrm{A}}}{\mathrm{j} \omega} \\
C_{\text {shunt }}=\frac{1}{L_{\mathrm{A}} \omega^{2}} \\
Q_{T}=\frac{1}{R_{\mathrm{A}}} \sqrt{\frac{L_{\mathrm{A}}}{C_{\text {shunt }}+C_{\text {chip }}}}
\end{gathered}
$$

The response of impedance matching $L C$ circuit, shown in Fig. 10, is designed at $25 \mathrm{MHz}$ with $3 \mathrm{~dB} \mathrm{BW}$ of $35 \mathrm{MHz}$. This impedance matching $L C$ circuit can be used with the RFID tag.

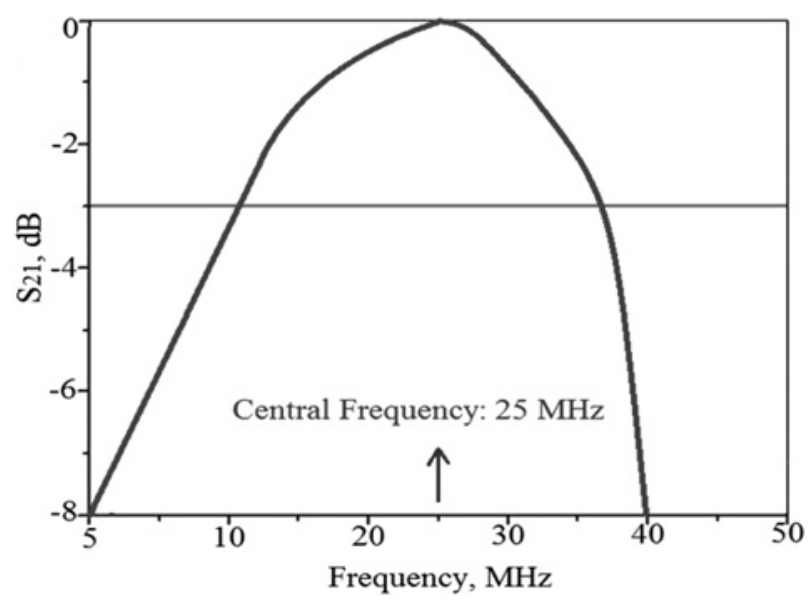

Fig. 10 Response of impedance matching LC circuit

\section{Conclusions}

A novel single-radiator card-type tag antenna is presented using series Hilbert-curve loop and matched stub for HF/UHF dual-band RFID application. By merging the series Hilbert-curve HF coil and the square loop UHF antenna a single radiator of RFID tag is obtained that meets the requirement of compactness and HF/UHF dual-band operation. Good broadband and circular polarisation performance is realised with a miniature physical footprint which is easy to fabricate using conventional manufacturing techniques. The tag operates over the UHF-band $(400 \mathrm{MHz}-1 \mathrm{GHz})$ for 
return-loss better than $-10 \mathrm{~dB}$. The inductive impedance at various frequencies in its operating band enables the matching network to be designed to integrate the RFID chip. The RFID tag has predominately quasi-omnidirectional radiation characteristics in both orthogonal $x y$ - and $y z$-planes, which makes it applicable in various applications at HF/UHF-bands.

\section{References}

1 Lu, J.H., Chang, B.S.: 'Planar circularly polarized tag antenna with compact operation for UHF RFID application', J. Electromagn. Waves Appl., 2013, 27, (15), pp. 1882-1891

2 Lu, J.H., Zheng, G.T.: 'Planar broadband tag antenna mounted on the metallic material for UHF RFID system', IEEE Antennas Wirel. Propag. Lett., 2011, 10, pp. $1405-1408$

3 Lu, J.H., Su, J.Y.: 'Planar loop tag antenna with bandwidth enhancement for UHF RFID system', Microw Opt. Technol. Lett, 2011, 53, (11), pp. 2711-2713

4 Keskilammi, M., Kivikoski, M.: 'Using text as a meander line for RFID transponder antennas', IEEE Antennas Wirel. Propag. Lett., 2004, 3, pp. 372-374

5 Son, H.W., Pyo, C.S.: 'Design of RFID tag antennas using an inductively coupled feed', Electron. Lett., 2005, 41, (18), pp. 994-996

6 Rao, K.V.S., Nikitin, P.V., Lam, S.F.: 'Antenna design for UHF RFID tags: a review and a practical application', IEEE Trans. Antennas Propag., 2005, 53, (12), pp. 3870-3876

7 Son, H.W., Choi, G.Y., Pyo, C.S.: 'Design of wideband RFID tag antenna for metallic surfaces', Electron. Lett., 2006, 42, (5), pp. 263-265

8 Ahn, J., Jang, H., Moon, H., et al.: 'Inductively coupled compact RFID tag antenna at $910 \mathrm{MHz}$ with near-isotopic radar cross-section (RCS) patterns', IEEE Antennas Wirel. Propag. Lett., 2007, 6, pp. 518-520

9 Hu, S., Law, C.L., Dou, W.: 'Petaloid antenna for passive UWB-RFID tags', Electron. Lett., 2007, 43, (22), pp. 1174-1176

10 Loo, C.H., Elmahgoub, K., Yang, F., et al.: 'Chip impedance matching for UHF tag antenna design', Progr. Electromagn. Res., 2008, 81, pp. 359-370

11 Marrocco, G.: 'RFID antennas for the UHF remote monitoring of human subjects', IEEE Trans. Antennas Propag., 2008, 55, (6), pp. 1862-1870

12 Calabrese, C., Marrocco, G.: 'Meandered-slot antennas for sensor-RFID tags', IEEE Antennas Wirel. Propag. Lett., 2008, 7, pp. 5-8

13 Paredes, F., Zamora, G., Herraiz-Martinez, F.J., et al.: 'Dual-band UHF-RFID tags based on meander-line antennas loaded with spiral resonators', IEEE Antennas Wirel. Propag. Lett., 2011, 10, pp. 768-771

14 Kim, D., Yeo, J.: 'Dual-band long-range passive RFID tag antenna using an AMC ground plane', IEEE Trans. Antennas Propag., 2012, 60, (6), pp. 2620-2626

15 Merilampi, S.L., Virkki, J., Ukkonen, L., et al.: 'Testing the effects of temperature and humidity on printed passive UHF RFID tags on paper substrate', Int. J. Electron., 2013, 101, (5), pp. 711-730

16 Allen, M.L., Jaakkola, K., Nummila, K., et al.: 'Applicability of metallic nanoparticle inks in RFID applications', IEEE Trans. Compon. Packag. Technol., 2009, 32, (2), pp. 325-332

17 Toccafondi, A., Giovampaola, C.D., Mariottini, F., et al. 'UHF-HF RFID integrated tag for moving vehicle identification'. IEEE Antennas and Propagation Society Int. Symp. Digest, 2009, pp. 1-4

18 Leong, K.S., Ng, M.L., Cole, P.H.: 'Miniaturization of dual frequency RFID antenna with high frequency ratio'. IEEE Antennas and Propagation Society Int. Symp. Digest, 2011, pp. 5475-5478

19 Mayer, L.W., Scholtz, A.L.: 'A Dual-band HF/UHF antenna for RFID tags'. Proc. IEEE 68th Vehicular Tech. Conf., 2008, pp. 1-5
20 Iliev, P., Thuc, P.L., Luxey, C., et al.: 'Dual-band HF-UHF RFID tag antenna', Electron. Lett., 2009, 45, pp. 439-441

21 Zeng, R.H., Chu, Q.X.: 'A compact slot-coupled dual-band RFID tag antenna', Microw. Opt. Technol. Lett., 2009, 51, (9), pp. 2046-2048

22 Lee, Y.C., Sun, J.S.: 'A fractal dipole tag antenna for RFID dual-band application', Microw. Opt. Technol. Lett., 2008, 50, (7), pp. 1963-1966

23 Kuo, J.S., Wang, J.J., Huang, C.Y.: 'Dual-frequency antenna for RFID tags with complementary characteristic', Microw. Opt. Technol. Lett., 2007, 49, (6), pp. 1396-1398

24 Paredes, F., Gonzàlez, G.Z., Bonache, J., et al.: 'Dual-band impedance-matching networks based on split-ring resonators for applications in RF identification (RFID)', IEEE Trans. Microw. Theory Tech., 2010, 58, (5), pp. 1159-1166

25 Nishioka, Y., Hitomi, K., Okegawa, H., et al.: 'Novel antenna configuration for HF and UHF band hybrid card-type RFID tags'. European Conf. on Antennas and Propagation (EuCAP), 2010, pp. 1-5

26 Ma, Z.L., Jiang, L.J., Xi, J., et al.: 'A single-layer compact HF-UHF dual-band RFID tag antenna', IEEE Antennas Wirel. Propag. Lett., 2012, 11, pp. 1257-1260

27 Deleruyelle, T., Pannier, P., Egels, P.M., et al.: 'Dual band mono-chip HF-UHF tag antenna'. Antennas and Propagation Society Int. Symp. (APSURSI), 2010, pp. 1-4

28 Attaran, A., Rashidzadeh, R., Muscedere, R.: 'Chipless RFID tag using RF MEMS switch', Electron. Lett., 2014, 50, (23), pp. 1720-1722

29 Ouattara, Y.B., Hamouda, C., Poussot, B., et al.: 'Compact diversity antenna for UHF RFID readers', Electron. Lett., 2012, 48, (16), pp. 975-977

30 Pan, Y., Zheng, L., Liu, H.J., et al.: 'Directly-fed single-layer wideband RFID reader antenna', Electron. Lett., 2012, 48, (11), pp. 607-608

31 Du, G.H., Tang, T., Deng, Y.: 'Dual-band metal skin UHF RFID tag antenna', Electron. Lett., 2013, 49, (14), pp. 858-860

32 Anguera, J., Puente, C., Martínez, E., et al.: 'The fractal Hilbert monopole: a two-dimensional wire', Microw. Opt. Technol. Lett., 2003, 36, (2), pp. 102-104

33 Zhu, J., Hoorfar, A., Engheta, N.: 'Feed-point effects in Hilbert-curve antennas' IEEE Antennas and Propagation Society Int. Symp., URSI Digest, San Antonio, Texas, June 2002

34 Anguera, J., Puente, C., Borja, C., et al.: 'Fractal-shaped antennas: a review', Wiley Encycl. RF Microw. Eng., 2005, 2, pp. 1620-1635

35 Gala, D., Soler, J., Puente, C., et al.: 'Miniature microstrip patch antenna loaded with a space-filling line based on the fractal Hilbert curve', Microw. Opt. Technol. Lett., 2003, 38, (4), pp. 311-312

36 Sanz, I., Anguera, J., Andújar, A., et al.: 'The Hilbert monopole revisited' European Conf. on Antennas and Propagation, EuCAP 2010, Barcelona, Spain

37 Vinoy, K.J., Jose, K.A., Varadan, V.K., et al.: 'Hilbert curve fractal antenna: a small resonant antenna for VHF/UHF applications', Microw. Opt. Technol. Lett., 2001, 29, (4), pp. 215-219

38 Vinoy, K.J., Jose, K.A., Varadan, V.K., et al.: 'Resonant frequency of Hilbert curve fractal antenna'. IEEE Antennas and Propagation Society Int. Symp., 2001, vol. 3 , pp. 648-651

39 Azad, M.Z., Ali, M.: 'A miniaturized Hilbert PIFA for dual-band mobile wireless applications', IEEE Antennas Wirel. Propag. Lett., 2005, 4, no., pp. 59-62

40 Anguera, J., Andújar, A., Huynh, M.C., et al.: 'Advances in antenna technology for wireless handheld devices', International Journal of Antennas and Propagation, 2013, 2013, Article ID 838364, p. 25, http://dx.doi.org/10.1155/2013/838364

41 Liu, J.C., Zeng, B.H., Chen, I., et al.: 'An inductive self-complementary Hilbert-curve antenna for UHF RFID broadband and circular-polarization tags', Progr. Electromagn. Res. B, 2009, 6, pp. 433-443

42 Ansoft HFSS, www.ansoft.com/products/hf/hfss

43 Basat, S., Bhattacharya, S., Rida, A., et al.: 'Fabrication and assembly of a novel high-efficiency UHF RFID tag on flexible LCP substrate'. IEEE Electronic Components and Technology Conf., 2006, pp. 1352-1355

44 Specifications, ISO15693, ISO18000-3, Elastic RFID Tech Co 